\title{
BMJ Open Needs of informal caregivers across the caregiving course in amyotrophic lateral sclerosis: a qualitative analysis
}

\author{
Miriam Galvin, ${ }^{1}$ Sile Carney, ${ }^{1,2}$ Bernie Corr, ${ }^{3}$ Iain Mays, ${ }^{1,2}$ Niall Pender, ${ }^{2}$ \\ Orla Hardiman ${ }^{1,3}$
}

To cite: Galvin M, Carney S, Corr B, et al. Needs of informal caregivers across the caregiving course in amyotrophic lateral sclerosis: a qualitative analysis. BMJ Open 2018;8:e018721. doi:10.1136/ bmjopen-2017-018721

- Prepublication history for this paper is available online. To view these files, please visit the journal online (http://dx.doi. org/10.1136/bmjopen-2017018721).

Received 24 July 2017 Revised 15 November 2017 Accepted 21 November 2017

Check for updates

${ }^{1}$ Academic Unit of Neurology, Trinity Biomedical Sciences Institute, Trinity College Dublin, Dublin, Ireland

${ }^{2}$ Department of Psychology, Beaumont Hospital, Dublin, Ireland

${ }^{3}$ Department of Neurology, National Neuroscience Centre, Beaumont Hospital, Dublin, Ireland

Correspondence to

Dr Miriam Galvin;

galvinmi@tcd.ie

\section{ABSTRACT}

Objectives Amyotrophic lateral sclerosis (ALS), also known as motor neuron disease (MND), is a debilitating terminal condition. Informal caregivers are key figures in ALS care provision. The physical, psychological and emotional impact of providing care in the home requires appropriate assistance and support. The objective of this analysis is to explore the needs of informal ALS caregivers across the caregiving course.

Design In an open-ended question as part of a semistructured interview, caregivers were asked what would help them in their role. Interviews took place on three occasions at 4-month to 6-month intervals. Demographic, burden and quality of life data were collected, in addition to the open-ended responses. We carried out descriptive statistical analysis and thematic analysis of qualitative data.

Setting and participants Home interviews at baseline $(n=81)$ and on two further occasions $(n=56, n=41)$ with informal caregivers of people with ALS attending the National ALS/MND Clinic at Beaumont Hospital, Dublin, Ireland.

Results The majority of caregivers were family members. Hours of care provided and caregiver burden increased across the interview series. Thematic analysis identified what would help them in their role, and needs related to external support and services, psychological-emotional factors, patient-related behaviours, a cure and 'nothing'. Themes were interconnected and their prevalence varied across the interview time points.

Conclusion This study has shown the consistency and adaptation in what caregivers identified as helpful in their role, across 12-18 months of a caregiving journey. Support needs are clearly defined, and change with time and the course of caregiving. Caregivers need support from family, friends and healthcare professionals in managing their tasks and the emotional demands of caregiving. Identifying the specific needs of informal caregivers should enable health professionals to provide tailored supportive interventions.

\section{INTRODUCTION}

Amyotrophic lateral sclerosis (ALS), also known as motor neuron disease (MND), is a progressive, neurodegenerative disease that impacts on the physical, communication and cognitive functioning of those affected. Management is

\section{Strengths and limitations of this study}

In an open-ended question caregivers identified what would help them in their role.

- Using an inductive approach the themes generated were derived from the data.

- This longitudinal study highlights the needs of informal caregivers of amyotrophic lateral sclerosis across the caregiving course.

- Responses to one open-ended question limited the opportunity to explore in greater depth what caregivers consider helpful in their role.

- It is important to explore caregiver needs at an individual level through in-depth interviews.

palliative, and treatment consists of symptom management and is aimed at maximising quality of life and minimising the burden of disease for patients and caregivers. ${ }^{1}$ There are approximately 110 new cases of ALS in Ireland each year, and at least $80 \%$ of these attend the National ALS/MND Clinic at Beaumont Hospital, Dublin. ${ }^{2}$

Informal caregivers are key figures in care provision, provide emotional and physical support to patients, and play a role in clinical decision-making in ALS. ${ }^{3}$ They require knowledge, skills and judgement to carry out the tasks of caregiving.

Caring for a partner or family member with a progressive neurological illness has been recognised as being a source of burden and psychological distress, with impaired quality of life. ${ }^{45}$ In ALS, patients' physical, cognitive and behavioural impairments can contribute substantially to the psychological and physical morbidity of the caregiver and affect caregiver burden. ${ }^{6}$ Caregiver burden encompasses different dimensions. Objective burden represents the tasks required of caregivers and time spent caregiving. Subjective burden is the perceived impact of the objective burden and the caregivers' 
own perception of their experience of their caregiving roles. ${ }^{89}$

Caregivers of people with ALS need emotional support, someone to talk to, information about the disease and its process, training, availability of respite care, counselling, and access to trained paid-for caregivers. ${ }^{410}$ A function of paid-for inhome care is to relieve burden and provide a period of relief from the caring role. However, the need for outside help may at times conflict with the need to preserve independence, dignity and familiar aspects of life. ${ }^{11}$ Williams et al ${ }^{12}$ represented a trajectory of ALS caregiver need: from early coping and adjustment, maintenance, transition to end stage, and coping with change and loss. The needs of caregivers are continuously evolving from diagnosis, as the disease progresses.

\section{Aim}

The aim of this analysis is to explore the needs of informal ALS caregivers across the caregiving course.

\section{METHODS}

\section{Participants}

Informal caregivers of people with ALS attending the specialist National ALS/MND Clinic multidisciplinary clinic (MDC) at Beaumont Hospital, Dublin, were recruited to the study. They were identified by the person with ALS as his/her primary informal caregiver, over 18 years of age, and providing unpaid care and assistance to them. Caregivers were consecutively recruited at outpatient clinic appointments. They were approached by a research assistant (IM) and provided with information about the research study. Those who expressed an interest in participating were given an information sheet, and contacted by phone to answer any queries, confirm agreement to participate and to arrange an interview. Informed written consent was obtained from all participants at the time of interview.

Patients were a mix of prevalent and incident cases, and their clinical details were available through the National ALS Registry, for which they had consented to inclusion of their codified clinical and demographic data.

\section{Data collection}

Pilot-tested, semistructured interviews were carried out at baseline (time 1) and on a further two occasions (time 2 , time 3), at 4-month to 6-month intervals, between May 2013 and November 2014. Interviews lasted approximately 1 hour and were conducted with the caregiver only, in his/her own home by a male assistant psychologist (IM) or a female health services researcher (MG), both members of the research team.

Information was collected on a range of caregiver demographics, burden and quality of life. Caregiver burden was assessed using the Zarit Burden Interview (ZBI). ${ }^{13}$ The ZBI is a self-report instrument that assesses burden associated with patients' behaviour and functional impairment, and the impact of caregiving on caregivers' lives. The higher the total score (scale of $0-88$ ) the higher the level of perceived burden.

The McGill Quality of Life Single-Item Scale $(\text { MQoL-SIS })^{14}$ is a single-item numerical rating scale (0 'very bad' to 10 'excellent') constructed to measure self-reported quality of life. Higher scores are indicative of greater subjective well-being and quality of life.

Qualitative data were collected from an open-ended question-in your role as a caregiver what would help you at the moment - devised in consultation with a key informant with clinical and research expertise, the MND clinical nurse specialist working in the Dublin MDC (BC). Responses to the open-ended questions and any related field notes were recorded in written format by the interviewer.

\section{Data analysis}

This analysis is based on data from caregivers who responded to that open-ended question, relative to each of the three interview time points. Descriptive statistical analyses performed using SPSS V. $22^{15}$ summarised the demographic and clinical data, characteristics of the caregiver and patient cohorts, and measures of caregiver burden and quality of life.

From an essentialist perspective, thematic analysis was used to identify patterns in the qualitative data. Employing an inductive approach, we identified elements in the text responses, which formed the basis for data-developed themes, the meanings of which were then interpreted. Two coders took part in a multiphase process including initial coding, theme development, review and definition. ${ }^{16}$ Two members of the research team (SC, MG) independently coded the responses and developed the code structure. Differences and similarities across the data set were explored through a constant comparative approach facilitating an iterative examination of findings, with discussion on points of agreement/disagreement leading to consensual validation. Reflexivity was maintained by looking at the data and their interpretation for competing conclusions. ${ }^{17}$ Audit trails were developed using reflexive memos and codebooks. The codes generated and themes constructed were reviewed for credibility of findings established based on clinical experience (BC). Data analysis software NVivo V.11 ${ }^{18}$ was used to collate and manage the qualitative data.

\section{RESULTS}

\section{Caregiver and patient characteristics}

Table 1 summarises the characteristics of caregivers and the patients for whom they provided care. Eighty-one caregivers responded to the open-ended question at their first interview. There was $31 \%$ attrition between the first and second interviews, with $26.8 \%$ fall-off from the second to the third. This was mainly attributed to increased burden, the time commitment of research participation and accruing disability of patients over time.

This was a largely female and spousal/partner cohort of caregivers, living with the patient for whom they provided 
Table 1 Characteristics of patients and caregivers

\begin{tabular}{|c|c|c|c|c|c|c|}
\hline \multirow[b]{3}{*}{$\mathbf{n}$} & \multicolumn{2}{|c|}{ Time 1} & \multicolumn{2}{|c|}{ Time 2} & \multicolumn{2}{|c|}{ Time 3} \\
\hline & \multicolumn{2}{|l|}{81} & \multicolumn{2}{|l|}{56} & \multicolumn{2}{|l|}{41} \\
\hline & $\mathbf{n}$ & $\%$ & $\mathbf{n}$ & $\%$ & $\mathbf{n}$ & $\%$ \\
\hline \multicolumn{7}{|l|}{ Sex } \\
\hline Male & 24 & 29.6 & 18 & 32.1 & 13 & 31.7 \\
\hline \multicolumn{7}{|l|}{ Age (years) } \\
\hline Mean & & 54.9 & & 57.9 & & 61.2 \\
\hline SD & & 13.4 & & 10.6 & & 8.4 \\
\hline \multicolumn{7}{|l|}{ Relationship to the patient } \\
\hline Spouse/partner & 58 & 71.6 & 47 & 83.9 & 36 & 87.8 \\
\hline Yes & 67 & 82.7 & 50 & 89.3 & 38 & 92.7 \\
\hline No & 14 & 17.3 & 6 & 10.7 & 3 & 7.3 \\
\hline \multicolumn{7}{|l|}{ Principal economic status } \\
\hline Working for payment/profit & 36 & 44.4 & 23 & 41.1 & 13 & 31.7 \\
\hline Unemployed & 4 & 4.9 & 0 & 0.0 & 1 & 2.4 \\
\hline Looking after family/home & 18 & 22.2 & 17 & 30.4 & 11 & 26.8 \\
\hline Retired & 21 & 25.9 & 15 & 26.8 & 15 & 36.6 \\
\hline $\begin{array}{l}\text { Unable to work due to permanent } \\
\text { sickness or disability }\end{array}$ & 2 & 2.5 & 1 & 1.8 & 1 & 2.4 \\
\hline Poor & 2 & 2.5 & 5 & 8.9 & 3 & 7.3 \\
\hline \multicolumn{7}{|l|}{ Hours of care provided per week } \\
\hline Mean & & 46.9 & & 57.4 & & 50.2 \\
\hline $\mathrm{SD}$ & & 48.5 & & 52.0 & & 43.4 \\
\hline Median & & 26.5 & & 37.5 & & 41.0 \\
\hline \multicolumn{7}{|l|}{ Caregiver burden (ZBI) } \\
\hline Mean & & 27.2 & & 30.3 & & 31.0 \\
\hline SD & & 14.6 & & 14.1 & & 13.8 \\
\hline Median & & 26.0 & & 31.0 & & 29.5 \\
\hline \multicolumn{7}{|l|}{ Quality of life (MQoL-SIS) } \\
\hline Mean & & 5.7 & & 6.1 & & 6.1 \\
\hline \multicolumn{7}{|l|}{ Patients } \\
\hline \multicolumn{7}{|l|}{ Age (years) } \\
\hline Mean & & 64.9 & & 64.3 & & 64.5 \\
\hline $\mathrm{SD}$ & & 10.6 & & 10.2 & & 9.6 \\
\hline \multicolumn{7}{|l|}{ Sex } \\
\hline Male & 49 & 60.5 & 40 & 71.4 & 27 & 65.9 \\
\hline
\end{tabular}


Table 1 Continued

\begin{tabular}{|c|c|c|c|c|c|c|}
\hline \multirow[b]{3}{*}{$\mathbf{n}$} & \multicolumn{2}{|c|}{ Time 1} & \multicolumn{2}{|c|}{ Time 2} & \multicolumn{2}{|c|}{ Time 3} \\
\hline & \multicolumn{2}{|l|}{81} & \multicolumn{2}{|l|}{56} & \multicolumn{2}{|c|}{41} \\
\hline & $n$ & $\%$ & $n$ & $\%$ & $n$ & $\%$ \\
\hline Female & 32 & 39.5 & 16 & 28.6 & 14 & 34.1 \\
\hline \multicolumn{7}{|c|}{ Time from diagnosis to interview (months) } \\
\hline Mean & & 16.0 & & 24.8 & & 32.0 \\
\hline SD & & 21.0 & & 23.3 & & 25.0 \\
\hline Median & & 8.6 & & 16.5 & & 24.4 \\
\hline Range & & $1-136$ & & $6-141$ & & $11-145$ \\
\hline \multicolumn{7}{|l|}{ Site of onset } \\
\hline Bulbar & 20 & 24.7 & 11 & 19.6 & 8 & 19.5 \\
\hline Bulbar/cognitive & 1 & 1.2 & 0 & 0.0 & 0 & 0.0 \\
\hline Spinal & 55 & 67.9 & 39 & 69.6 & 30 & 73.2 \\
\hline Spinal/cognitive & 3 & 3.7 & 4 & 7.1 & 2 & 4.9 \\
\hline Respiratory & 2 & 2.5 & 2 & 3.6 & 1 & 2.4 \\
\hline \multicolumn{7}{|l|}{ MiToS stage } \\
\hline 0 & 46 & 56.8 & 23 & 41.1 & 14 & 34.1 \\
\hline 1 & 22 & 27.2 & 21 & 37.5 & 15 & 36.6 \\
\hline 2 & 9 & 11.1 & 6 & 10.7 & 5 & 12.2 \\
\hline 3 & 1 & 1.2 & 0 & 0.0 & 0 & 0.0 \\
\hline Not available & 3 & 3.7 & 6 & 10.7 & 7 & 17.1 \\
\hline
\end{tabular}

MiToS, Milano-Torino Staging system; MQoL-SIS, McGill Quality of Life Single-ltem Scale; ZBI, Zarit Burden Interview,

care. The mean age was 55 years (SD 13.3) at the first interview (table 1). The median number of hours of care provided per week was 26.5 hours (46.9). In terms of self-assessed health, $85 \%$ indicated their health was 'excellent, very good or good'. The mean quality of life score (MQoL-SIS) was 5.7. For this cohort the mean caregiver burden (ZBI) score at all three interviews exceeded the cut-off for categorisation of high burden, with a mean burden score of 24 or higher. ${ }^{619}$

At baseline, the mean age of the patients was 65 years (SD 10.6), the majority was male $(61 \%)$ and had spinal onset $(68 \%)$. The Milano-Torino (MiToS) staging criteria categorised $57 \%$ of patients at stage 0 of the disease, $27 \%$ at stage $1,11 \%$ at stage 2 and $1 \%$ at stage 3 , as per standardised protocol. ${ }^{20}$ The mean time from diagnosis was 16 months (median 8.6).

\section{Thematic analysis}

In the open-ended question, caregivers were asked: in your role as a caregiver what would help you at the moment? The responses coded and themes identified are a reflection of the entire data set. Five main themes and constituent subthemes were generated through the analysis (figure 1).

The five themes with selected supporting quotes are presented below, denoted by caregiver ID, relationship to patient and interview time point $(\mathrm{eg}, \# 1 \mathrm{cg}$, son, time 1)

\section{Theme 1: external support and assistance}

Caregivers mentioned a range of external support and assistance that would be helpful to them. These included health and social care services to the home, support from family and friends, aids and appliances, information, advice, training, and financial support.

'Home help' services, assistance with personal care and household tasks were identified in particular. Respondents commented on the ways in which care hours are distributed and organised. Time allocated for home help assistance is seen by some as not adequate, or flexible enough to cover the times when the caregiver needs it.

Somebody to sit with [patient] for a whole afternoon. My homecare is six hours but spread over the week. You can't do much in the time. (69cg, female spouse/ partner, time 1)

There is a need for oversight of the formal carers and care arrangements, and coordination of care hours supplied by external agencies.

A nurse to come in and see how the bed care is going, to analyse the carers and advise how things should be; it's hard to talk to the public health nurse about

'In Ireland at present 'home help services' comprise community-based health and social care workers who provide personal care, housework and cleaning services related to a designated patient. 


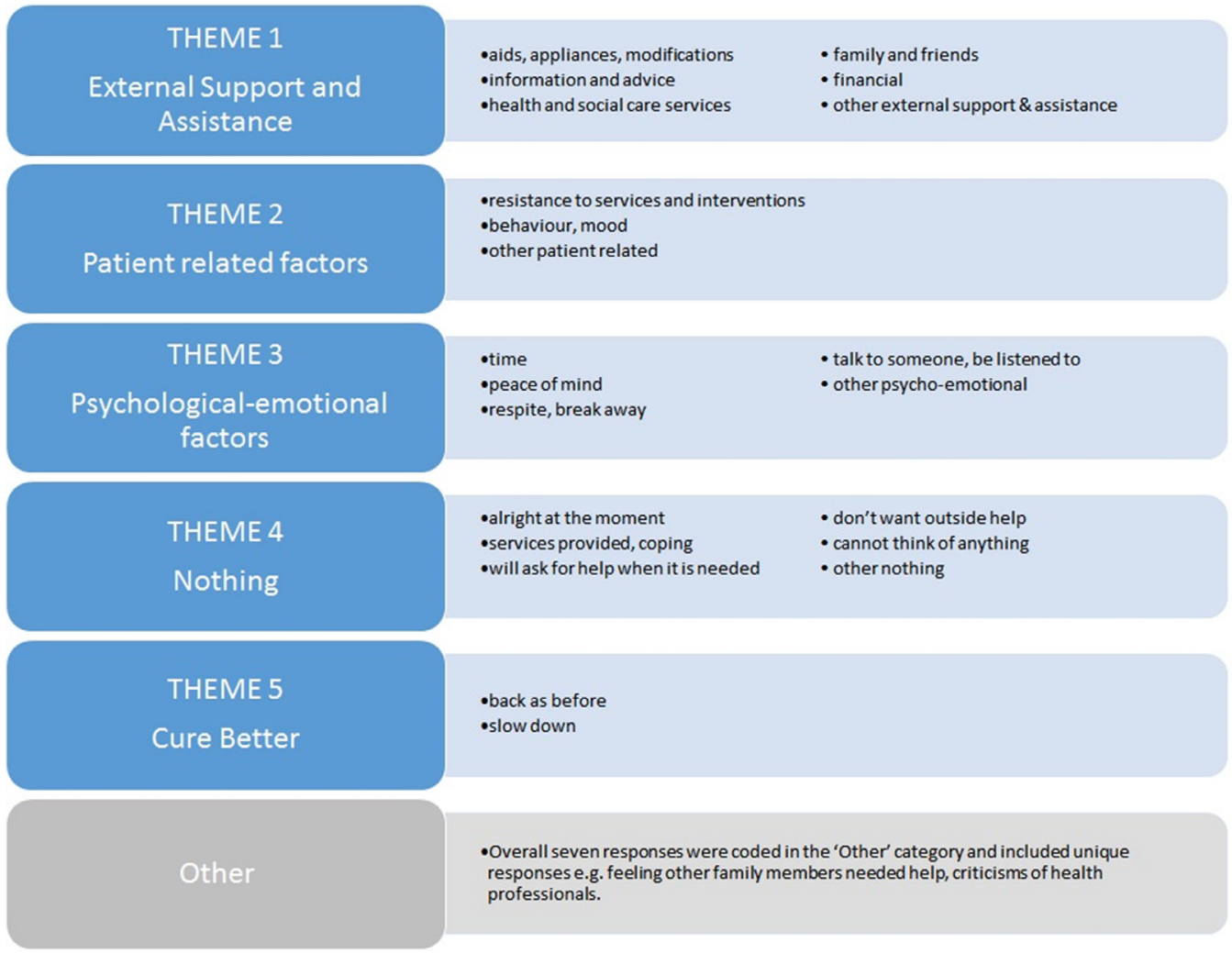

Figure 1 Themes and subthemes.

it and not have her in early in the morning to see what should be done. (85cg, female spouse/partner, time 2)

If we have greater control over our carers, we end up doing their timetables; for example bank holidays they always [make a mistake] and we have to sort it. (88cg, son, time 2)

The availability of appropriate appliances and a range of mobility, communication aids and home modifications is important.

...putting in a ramp at the kitchen there from the door to the gate. (83cg, male spouse/partner, time 2)

A wheelchair, a car that I could wheel him into it so we can start going places. (56cg, female spouse/partner, time 3)

Assistance and support from family and friends for 'small tasks' provide companionship for the patient and allow the caregiver time away. Financial assistance would alleviate some current and future concerns. Items mentioned included state benefit for caregivers, reduced cost of medical expenses through availability of the 'medical card' 'ii , and grants and funding for home modifications from the Irish Motor Neurone Disease Association (IMNDA) and the Irish Health Service Executive (HSE).

\footnotetext{
${ }^{\text {ii }}$ Medical cards allow people to access family doctor/general practitioner services, community health services, dental services, prescription medicine costs, hospital care and a range of other benefits free of charge.
}

There is a need for information about ALS, advice about what they should be doing and what to expect in the future, ways to navigate the health services, and training on how to perform specific tasks.

A blueprint for where to go for information and assistance. (55cg, male spouse/partner, time 1)

I think I'd have to know more about MND when it gets to this stage now...now I wonder how I make him feel at ease, if I knew how to care for him and handle it better, how to lift (him), to wash him. (28cg, female spouse/partner, time 3)

A bit more training in looking after someone; general personal maintenance a simple example is washing hair. I see myself as a husband caring for a wife (and not a proper carer). (53cg, male spouse/partner, time 1)

\section{Theme 2: patient-related factors}

Patients' acceptance of external services and an understanding of the caregivers' situation were mentioned as things that would help. Caregivers referred to patient resistance to formal care services and interventions, and outside involvement related to personal care, as a source of particular opposition.

If [patient] allowed other people to help; the thought that there's someone there, that he would be happy with them... (9cg, female spouse/partner, time 2) 
It's just if I physically had more hands, he doesn't let the carer help with personal hygiene, that's for me. (16cg, female spouse/partner, time 3)

Being able to talk about the care situation they faced had become more difficult and formerly open communication relationships had changed.

[It would be helpful] ...that we talk because if I don't, we build up resentment and it doesn't help, we've always talked but everything got difficult since the MND. (81cg, female spouse/partner, time 2)

In some cases there was a sense of the patient exerting control through manipulating situations, which created difficulties for the caregiver.

...if I go away for a weekend she will take Imodium so nobody has to take her to the commode but me, I know it's coming when I'm heading. For her relaxing more with others and additional carers in the future with certain types of caring, commode duty etc. (53cg, male spouse/partner, time 2)

\section{Theme 3: psychological-emotional factors}

Responses thematised here reflect a range of concerns, such as need for more time, less responsibility, peace of mind, respite, freedom, someone to talk to and to be listened to. It would be helpful for someone to notice and be attentive to them.

For [patient] not to rely on me quite as much as she does. (53cg, male spouse/partner, time 2)

Somebody asking about how I'm doing. (75cg, female spouse/partner, time 1)

I'd like to not be here as much as I am. $(57 \mathrm{cg}$, daughter, time 1)

There can be competing work and family responsibilities, and the decreasing resource of time can mean neglecting those and often one's own needs.

Time. Time with my mam, time alone, time with the kids, time with my husband; time in every aspect. If I'd have time I'd be able to get a handle on things, to get organised. (82cg, daughter, time 1)

I'm more conscious of it this year, maintaining some sort of existence away from here, I haven't been successful with it yet... (98cg, son, time 2)

Probably a little more time off in looking after him... to have an easy mind and go away. (9cg, female spouse/partner, time 3)

\section{Theme 4: nothing}

Responses categorised under this theme comprised comments from caregivers who said they were fine with how things were going for them, and they were coping on their own and/or with what they feel was adequate support.
Nothing at the moment. $(008 \mathrm{cg}$, female spouse/partner, time 1)

Nothing really. We cope and we manage. (35cg, female spouse/partner, time 1)

I can't think of anything, I think everything has been provided for her. $(52 \mathrm{cg}$, male spouse/partner, time 3)

Everything is going fine I don't have a problem, we've got the aids we need at the moment from the HSE [Irish Health Service] and IMNDA [MND charity]. (64cg male spouse/partner, time 2)

Many commented that they did not want outside help and wanted to continue being the main care provider, for as long as possible, while others indicated that they will ask for help when they feel it is necessary.

Nothing else, they've asked do I want anyone in and I'm fine, I'd rather do it myself. (56cg, female spouse/partner, time 3)

A number of responses implied acceptance or perhaps resignation, such as "we are where we are"; or there was a sense of despair: "is there anything that could help me?"

Often caregivers simply responded "nothing" would help them, which could be interpreted as either despairing or coping, as there were no probes to this question.

\section{Theme 5: cure better}

For some respondents a cure, the patient getting better or to go back to what she/he used to be would help.

If he got better. If the illness would plateau for a while and just relax. I can't think of the next step, I just want it to calm down. (81cg, female spouse/partner, time 1)

...you'd like to go back to normal as things were. (47cg, female parent, time 2$)$

\section{Prevalence of themes across interview time points}

Some open-ended responses could be multiply coded comprising elements pertaining to a number of themes. Quantification in terms of number and percentage of caregivers coded to each theme, and prevalence across the three interviews, provides an overview of the qualitative material. The prevalence of themes derived from the coded data at the three interview time points is presented in table 2 and figure 2.

Issues related to external support and assistance were mentioned by a majority of caregivers, especially at the second interview, when $70 \%$ indicated that some form of outside support, for example, services, family and financial, would be of help to them at that time.

Nothing was the second most frequently mentioned theme overall and at the first and third interviews in particular. Patient-related factors increased in frequency from time $1(7 \%)$ to time $2(16 \%)$. Responses thematised as psychological-emotional factors remained relatively stable, being mentioned by approximately $23 \%$ of caregivers across the 
Table 2 Prevalence of themes at each interview time point*

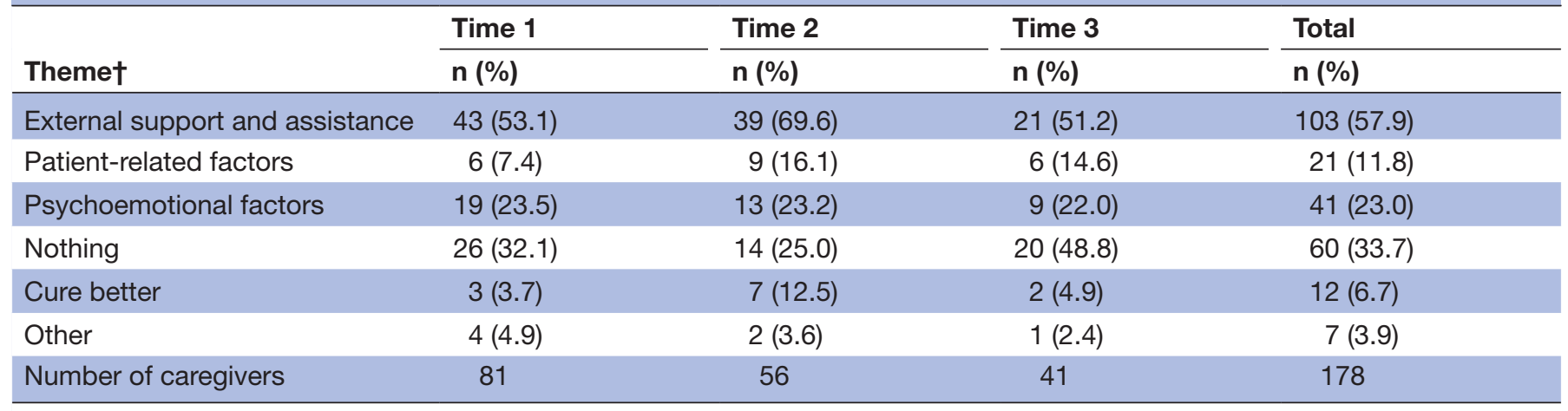

Approximate interview interval dependent on patient condition and caregiver availability.

*Interview timeline: time 1=baseline; time 2=baseline + 4-6 months; time 3=time 2 + 4-6 months.

†Themes by \% of CGs at each interview.

CG, caregivers.

three interviews. Suggestions that a cure or improvement in the condition would help were mentioned by $13 \%$ at the second interview, with fewer mentions at the first and last interviews.

\section{Connection}

Responses could contain elements pertaining to more than one theme, and thus some themes were connected to each other. These connections are illustrated in the following thematic contiguity maps, representing the relationships between themes at each interview (figure 3A,B,C). As an example, 43 caregivers at the first interview mentioned external support would be helpful to them, and of these 12 also commented that having psychological-emotional issues addressed would be helpful (figure 3A).

Across the interviews caregivers' need for external support and assistance (theme 1) was most often mentioned in connection with psychological-emotional support (theme 3 ), and patient behaviour and resistance (theme 2).

\section{DISCUSSION}

This multimethod study with the qualitative strand prioritised has identified what caregivers suggest would help them in their role, at three interviews across approximately 12-18 months of a caregiving journey. While the practice of caregiving can exist before formal diagnosis, the time from diagnosis is used here as start of the explicit caregiving course.

A reduction in the number of caregiver respondents over time was mainly attributed to the increased burden and time commitment of research participation, and increased disability of patients. The proportion of adult children respondents decreased considerably, over the

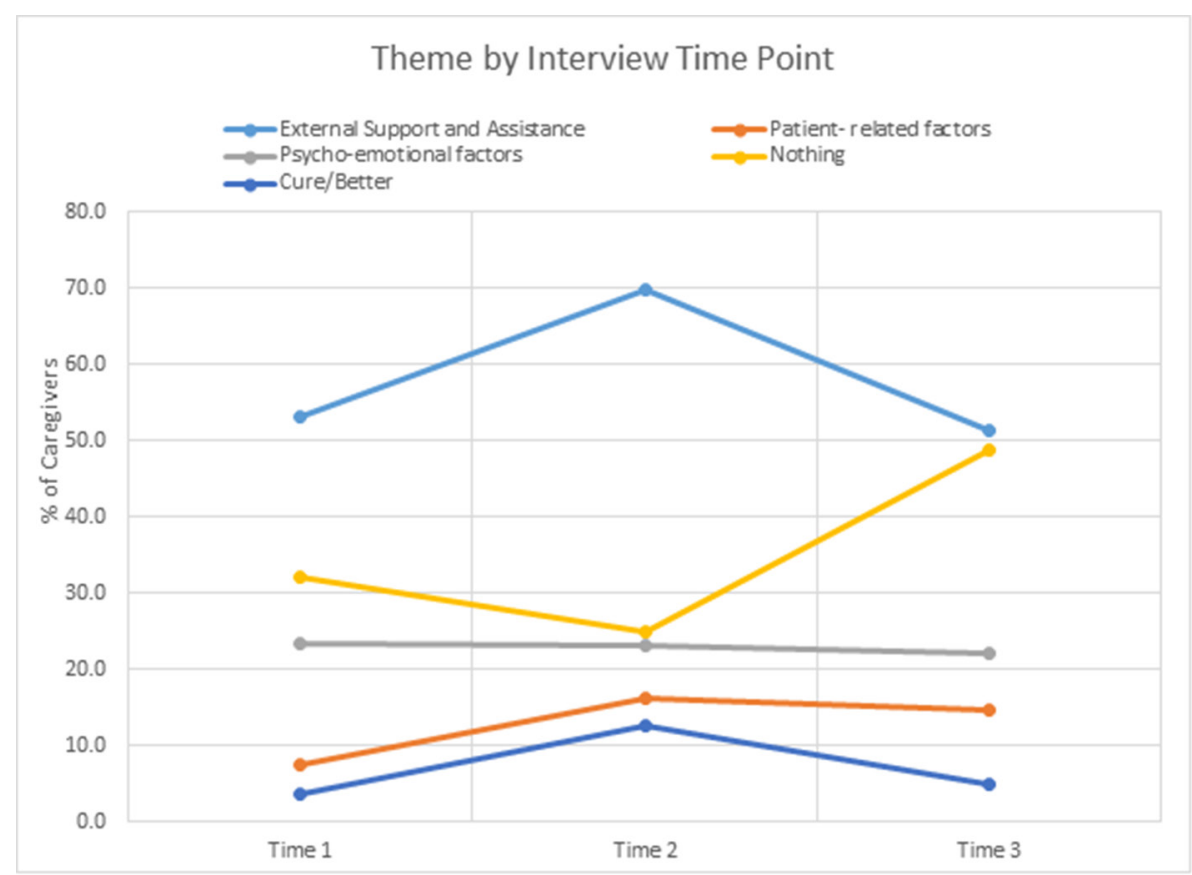

Figure 2 Five main themes at each interview time point. 


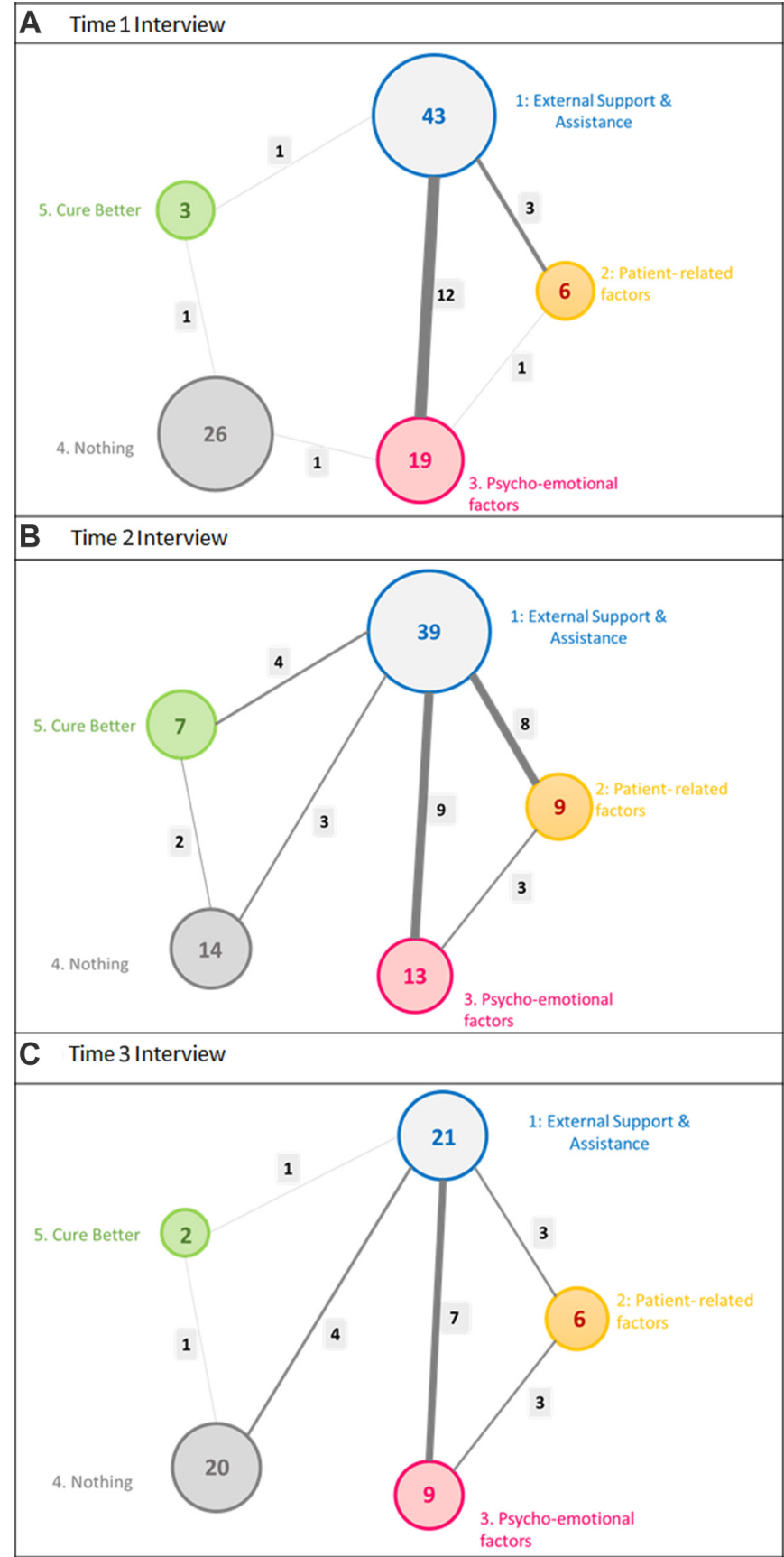

Figure 3 Thematic contiguity map: (A) time 1 interview, (B) time 2 interview and $(C)$ time 3 interview.

three interviews. The percentage of caregivers in employment declined. There was a deterioration in self-assessed health and an increase in the median number of hours spent caregiving per week. Other research has shown that caregivers of people with ALS have persisting high strain, their psychological distress increases significantly, ${ }^{21}{ }^{22}$ and their quality of life declines over time. ${ }^{23}$ In this study caregiver burden as measured by the ZBI was high at all three time points, with the respective mean scores exceeding the statistically derived cut-off for high burden. ${ }^{6}{ }^{19}$ The mean quality of life (MQoL-SIS) score of the caregiver cohorts was in the middle of the range $(0-10)$ at all three interviews.
These informal ALS caregivers identified external support and assistance, psychological-emotional factors, less patient resistance to outside services, and a cure for ALS or at least respite from its progression as things that would help them. Many responded that nothing would help, which was largely described as coping with the current caregiving situation, with a view to accessing services if/when they considered appropriate for their own caregiving context. Others simply said "nothing" would help them at present.

External support and assistance was the most frequently mentioned theme overall, and at each of the three time points, respectively. Its reduced prevalence at the third interview suggests that relevant external support required may have been in place by that time. Caregivers need services provided in flexible ways that suit their situations, and services to the home monitored for quality and performance. Caregivers also need internal resources, and a range of issues that would help them are thematised as psychological-emotional factors. These include someone to talk to and someone to listen to them, time away from caregiving and opportunities to pursue their own interests, peace of mind, and shared responsibility. The percentage of caregivers in this thematic category remained relatively consistent over the three interviews $(22 \%-23 \%)$.

Patient-related factors included uncooperative behaviours and resistance to external support and services. This resistance manifested in an over-reliance on the informal caregiver, refusal of services or unwillingness to engage when service providers were present. These features were present across the three time points, increasing after the first interview, and mentioned by $16 \%$ of caregivers at the second interview. Non-acceptance of external support and services compounds the difficulties caregivers face and increases the stress in an already strained context.

It is important to note however that many informal caregivers wished to do without outside services and assistance themselves, or at least postpone their intervention. Nothing was the second most frequently mentioned theme overall. The prevalence of this theme increased from the first interview (32\%) to the third interview, at which point $49 \%$ of caregivers suggested that nothing would be helpful, they were doing alright and/or had adequate services and support. The third interview was approximately mean 32 months (median 24 months) since a formal ALS diagnosis. Patients exerting control in care is an adaptive response to loss in ALS. ${ }^{24}$ This study confirms that caregivers exert control when availing of external services.

Within the theme cure better caregivers indicated that a cure for the disease, the return of their loved one to before the illness or a stabilising of the progression at least would be helpful. Compared with the second interview, there was less reference to these issues at the third time point, as perhaps people had accepted or were resigned to the course of the disease. 
The needs of ALS caregivers continuously evolve as the disease progresses. ${ }^{12}$ Our findings concur with other research that shows that caregivers need support to enable them to provide care, for example, equipment and managing symptoms, and direct personal support for themselves, for example, emotional support. ${ }^{25}$ This study has found that what caregivers consider helpful is comparatively consistent, but the relative status of those needs changes over time and the course of caregiving (table 2 and figure 2). It is noticeable that at the second interview (mean 25/median 16.5 months since diagnosis), caregivers expressed increased need for external support and services, more patient-related resistance and non-acceptance than at the first interview. More were hoping for a cure for the disease, and fewer mentioned that they needed nothing and were alright the way they were. As noted above, the latter (nothing) was mentioned by almost one-third of caregivers at the first interview and approximately half of all respondents at the third interview; however, its prevalence at the second time point was $25 \%$. Perhaps this period of the caregiving course is one of increased needs, particular stress and task-load for ALS caregivers, and more help is required. It may be that during this phase there is a growing realisation of the actual and potential impact of the disease on the patient and family, awareness of the support required, and the challenges ahead. With time, caregivers and families may subsequently come to terms with the implications of the situation and have adjusted and modified their expectations for themselves and others. Accordingly with an integration of these changes, it appears needs alternately are addressed, stabilised and modified over the course of the caregiving trajectory.

Studies on caregiver burden consistently report two factors underlying its subjective assessment through the ZBI measure-personal strain and role strain. ${ }^{26}{ }^{27}$ There is a relationship between task-oriented care and caregiver psychosocial well-being, and a complex interplay between caregiver psychosocial needs and role-specific factors. ${ }^{28}$

The requirement for external support, psychological-emotional needs and patient-related factors are clearly related. External support and assistance could benefit the patient and positively affect the caregivers' ability to manage tasks and get time away from care duties and opportunities to do other things with that time. Patients' resistance to receiving outside assistance has implications for caregivers' well-being and task-load. Conflict of interests between patients and caregivers places caregivers in a difficult position of prioritising patients' needs above other commitments and their own well-being. With the focus on taking care of others, they may not consider seeking help for themselves, and healthcare professionals should discuss with them that the caregiving role is one for which they can seek support.

This study has highlighted the needs of informal caregivers and demonstrated both their consistency and modification across the caregiving course. We have illustrated the connections between the need for external support and services and internal resources and patients' behaviour and resistance to those services. We have shown that the relative status of these needs varies with time, and have identified a potential problematic mid-phase of caregiving in terminal illness. The findings from this study should inform the organisation and delivery of health and social services and enable healthcare professionals to tailor supportive interventions to those caring for people with ALS.

There are a number of limitations to this study. Findings relate to this caregiver cohort only. The reduction in the sample size over time could have introduced bias into those participating and to their responses. We have not sought to explain the impact of frontotemporal dementia and cognitive/behavioural impairment in patients, on caregiver needs. The presence of these states could influence needs thematised here under 'patient-related factors', with repercussion on caregivers' psychological and emotional health. As stated above responses thematised in this analysis as 'Nothing' include both positive and negative comments and would require more in-depth analysis to explore thematic ambiguity. Further research should explore caregiver needs at an individual level through in-depth interviews; establish whether those needs are being met; and examine associations of disease stage, patient cognitive/behavioural impairment, and relationship to the care recipient, caregiver burden and psychological health on the complex needs of caregivers.

\section{CONCLUSION}

Our findings show the interrelatedness of external and internal resource needs, and the impact of the caregiving role and associated personal strain on the lives of informal ALS caregivers. We have demonstrated the phasic nature of caregiver needs and identified a potentially problematic time at approximately $1.5-2$ years since formal ALS diagnosis. An understanding of the possible interrelationship and temporality of these needs and the sequential impact on the life of the caregiver is important. Supportive services and timing of interventions tend to be clinician-driven and led by the needs of the patient; however, the acceptance and ultimately compliance with these directives implicates the clinician, patient and caregiver/family.

Acknowledgements We would like to thank the caregivers who participated in this research, and Mark Heverin, Research Manager in the Academic Unit of Neurology, TCD.

Contributors MG designed and developed the study, analysed and interpreted the data, and drafted the initial manuscript. BC was involved in the development of the research question and interpretation of the data. IM and MG were involved in the acquisition of data. SC assisted with analysis and interpretation of data. MG, SC, $\mathrm{NP}$ and $\mathrm{OH}$ revised the drafts for intellectual content and edited the manuscript. All authors reviewed and approved the final draft.

Funding This research was supported by funding from the Irish Health Research Board Dublin (http://www.hrb.ie), as part of the HRB Interdisciplinary Capacity Enhancement Awards (ICE/2012/6), and the Clinical Management Grant from the American ALS Association (17-CM-324) (http://www.alsa.org). 
Competing interests $\mathrm{OH}$ is the Editor in Chief of the Amyotrophic Lateral Sclerosis and the Frontotemporal Degenerations journal, and is a member of the editorial board of the Journal of Neurology, Neurosurgery and Psychiatry.

Patient consent Obtained.

Ethics approval Ethical approval for this study was received from Beaumont Hospital Ethics (Medical Research) Committee (REC REF 12/84) and the Research Ethics Committee, Trinity College Dublin.

Provenance and peer review Not commissioned; externally peer reviewed.

Data sharing statement No additional data are available. The material generated and analysed during the current study cannot be made publicly available for reasons of privacy and confidentiality (Beaumont Hospital Medical Research Ethics Committee). However, access to de-identified data sets can be made available on request to Mr Mark Heverin (mark.heverin@tcd.ie).

Open Access This is an Open Access article distributed in accordance with the Creative Commons Attribution Non Commercial (CC BY-NC 4.0) license, which permits others to distribute, remix, adapt, build upon this work non-commercially, and license their derivative works on different terms, provided the original work is properly cited and the use is non-commercial. See: http://creativecommons.org/ licenses/by-nc/4.0/

(c) Article author(s) (or their employer(s) unless otherwise stated in the text of the article) 2018. All rights reserved. No commercial use is permitted unless otherwise expressly granted.

\section{REFERENCES}

1. Connolly S, Galvin M, Hardiman O. End-of-life management in patients with amyotrophic lateral sclerosis. Lancet Neurol 2015;14:435-42.

2. O'Toole O, Traynor BJ, Brennan P, et al. Epidemiology and clinical features of amyotrophic lateral sclerosis in Ireland between 1995 and 2004. J Neurol Neurosurg Psychiatry 2008;79:30-2.

3. Hogden A, Greenfield D, Nugus P, et al. What are the roles of carers in decision-making for amyotrophic lateral sclerosis multidisciplinary care? Patient Prefer Adherence 2013;7:171-81.

4. O'Brien MR, Whitehead B, Jack BA, et al. The need for support services for family carers of people with motor neurone disease (MND): views of current and former family caregivers a qualitative study. Disabil Rehabil 2012;34:247-56.

5. Goldstein LH, Atkins L, Landau S, et al. Predictors of psychological distress in carers of people with amyotrophic lateral sclerosis: a longitudinal study. Psychol Med 2006;36:865.

6. Burke T, Elamin M, Galvin M, et al. Erratum to: Caregiver burden in amyotrophic lateral sclerosis: a cross-sectional investigation of predictors. J Neurol 2015;262:2799-99.

7. Elamin M, Bede P, Byrne S, et al. Cognitive changes predict functional decline in ALS: a population-based longitudinal study. Neurology 2013;80:1590-7.

8. Jones SL. The association between objective and subjective caregiver burden. Arch Psychiatr Nurs 1996;10:77-84.
9. Montgomery RJV, Gonyea JG, Hooyman NR. Caregiving and the experience of subjective and objective Burden. Fam Relat 1985;34:19-26.

10. Bolmsjö I, Hermérn G. Conflicts of interest: experiences of close relatives of patients suffering from amyotrophic lateral sclerosis. Nurs Ethics 2003;10:186-98.

11. Grande GE, Todd CJ, Barclay SI. Support needs in the last year of life: patient and carer dilemmas. Palliat Med 1997;11:202-8.

12. Williams MT, Donnelly JP, Holmlund T, et al. ALS: Family caregiver needs and quality of life. Amyotroph Lateral Scler 2008;9:279-86.

13. Zarit SH, Reever KE, Bach-Peterson J. Relatives of the impaired elderly: correlates of feelings of burden. Gerontologist 1980;20:649-55.

14. Cohen SR, Mount BM, Strobel MG, et al. The McGill Quality of Life Questionnaire: a measure of quality of life appropriate for people with advanced disease. A preliminary study of validity and acceptability. Palliat Med 1995;9:207-19.

15. IBM Corp. IBM SPSS Statistics for Windows. Version 22.0. Armonk, NY: IBM Corp.2013.

16. Braun V, Clarke V. Using thematic analysis in psychology. Qual Res Psychol 2006;3:77-101.

17. Malterud K. Qualitative research: standards, challenges, and guidelines. The Lancet 2001;358:483-8.

18. QSR International. NVivo qualitative data analysis software. Version 11. QSR International Pty Ltd. 2015.

19. Schreiner AS, Morimoto T, Arai Y, et al. Assessing family caregiver's mental health using a statistically derived cut-off score for the Zarit Burden Interview. Aging Ment Health 2006;10:107-11.

20. Chiò A, Hammond ER, Mora G, et al. Development and evaluation of a clinical staging system for amyotrophic lateral sclerosis. J Neurol Neurosurg Psychiatry 2015;86:38-44.

21. Bruletti G, Comini L, Scalvini S, et al. A two-year longitudinal study on strain and needs in caregivers of advanced ALS patients. Amyotroph Lateral Scler Frontotemporal Degener 2015;16:187-95.

22. Goldstein LH, Atkins L, Landau S, et al. Predictors of psychological distress in carers of people with amyotrophic lateral sclerosis: a longitudinal study. Psychol Med 2006;36:865-75.

23. Roach AR, Averill AJ, Segerstrom SC, et al. The dynamics of quality of life in ALS patients and caregivers. Ann Behav Med 2009;37:197-206.

24. Foley G, Timonen V, Hardiman O. Exerting control and adapting to loss in amyotrophic lateral sclerosis. Soc Sci Med 2014;101:113-9.

25. Ewing G, Grande G. National Association for Hospice at Home. Development of a Carer Support Needs Assessment Tool (CSNAT) for end-of-life care practice at home: a qualitative study. Palliat Med 2013;27:244-56.

26. Siegert RJ, Jackson DM, Tennant A, et al. Factor analysis and Rasch analysis of the Zarit Burden Interview for acquired brain injury carer research. J Rehabil Med 2010;42:302-9.

27. Ankri J, Andrieu S, Beaufils B, et al. Beyond the global score of the Zarit Burden Interview: useful dimensions for clinicians. Int $J$ Geriatr Psychiatry 2005;20:254-60.

28. Galvin M, Corr B, Madden C, et al. Caregiving in ALS - a mixed methods approach to the study of Burden. BMC Palliat Care 2016;15:81. 